\title{
Rocket Observations of Visible and Ultraviolet Dayglow Features
}

\author{
T. Nagata, T. Tohmatsu and T. Ogawa \\ Geophysics Research Laboratory, University of Tokyo \\ (Received July 27, 1968)
}

\begin{abstract}
Rocket results are presented on visible and ultraviolet dayglow observed in the altitude range of $80-350 \mathrm{~km}$, for different values of solar zenith distance. Theoretical interpretotions are given on the basis of calculations made for emission rates for various excitation mechanisms, also using results of simultaneous measurements of electron density and electron temperature.
\end{abstract}

\section{Introduction}

In the previous paper ${ }^{1)}$, the writers presented the rocket results on the OI $6300 \AA$ line and on the $\mathrm{N}_{2}{ }^{+} 3914 \AA$ band in the dayglow. The experiment was repeated in the hour when the zenith distance of the Sun was large (approximately $90^{\circ}$ ). Also the present report includes the features of other visible and ultraviolet glow observed at Uchinoura, Japan. The names of vehicle used in the experiments were listed in Table 1 with the flight date, the time of launching, the solar zenith distance, and with the colors of the photometer flown.

Table 1. The Sounding Rocket Experiments of the Day Airglow, Uchinoura, Japan $\left(131^{\circ} 05^{\prime} \mathrm{E}\right.$, $\left.31^{\circ} 15^{\prime} \mathrm{N}\right)$

\begin{tabular}{c|c|c|c|c}
\hline Vehicle & Date & Time (JST) & $\begin{array}{c}\text { Solar zenith } \\
\text { distance }\end{array}$ & Color \\
\hline L-3-2 & Jan. 31, 1965 & $14: 01$ & $54^{\circ}$ & $\begin{array}{c}2150 \AA \\
2000-3000 \AA\end{array}$ \\
\hline K-9M-9 & Mar. 27, 1965 & $14: 01$ & $37^{\circ}$ & $\begin{array}{c}6300 \AA \\
2500 \AA\end{array}$ \\
\hline K-9M-20 & Oct. 20, 1966 & $17: 25$ & $88^{\circ}-91^{\circ}$ & $\begin{array}{c}6300 \AA \\
2150 \AA\end{array}$ \\
\hline
\end{tabular}

The analysis of records proceeded on the theoretical background which took into consideration the various excitation mechanisms as listed in Table 2. Among the mechanisms of Table 2, the photoelectron excitation was not considered in the previous study ${ }^{1)}$ and was newly evaluated its contribution ${ }^{2}$. Also shown in Table 2 was the rank of the brightness from different mechanisms as expected from theory.

The electron density profiles which were measured simultaneously with the present dayglow observations are plotted in Fig. 3. They were used to determine the rate of the DR processes, the density of $\mathrm{N}_{2}{ }^{+}$, and further to evaluate the stopping power of electron-electron 
Tabel 2. The Mechanism of the Dayglow Excitation (The rank of contribution to the total brightness is indicated as I, II, and III)

\begin{tabular}{l|c|c|c|c|c}
\hline \multicolumn{1}{c|}{ Excitation Mechanism } & Symbol & $6300 \AA$ & $5577 \AA$ & $3914 \AA$ & UV \\
\hline $\begin{array}{l}\text { Resonance fluorescence of } \\
\text { solar radiations }\end{array}$ & RF & - & - & I & (I) \\
\hline $\begin{array}{l}\text { Simultaneous ionization } \\
\text { and excitation by solar } \\
\text { ultraviolet radiations }\end{array}$ & SIE & - & - & $\begin{array}{c}\text { II } \\
\text { III } \\
\text { (sunset) }\end{array}$ & - \\
\hline $\begin{array}{l}\text { Simultaneous dissociation } \\
\text { and excitation (Schumann- } \\
\text { Runge dissociation) }\end{array}$ & SR & I & (III) & - & - \\
\hline $\begin{array}{l}\text { Photoelectron impact } \\
\text { excitations }\end{array}$ & PE & II & (I) & $\begin{array}{c}\text { II } \\
\text { III } \\
\text { (day) }\end{array}$ & (II) \\
\hline $\begin{array}{l}\text { Chemiluminescence } \\
\text { (Dissociative recombination) }\end{array}$ & DR & III & (II) & - & - \\
\hline
\end{tabular}

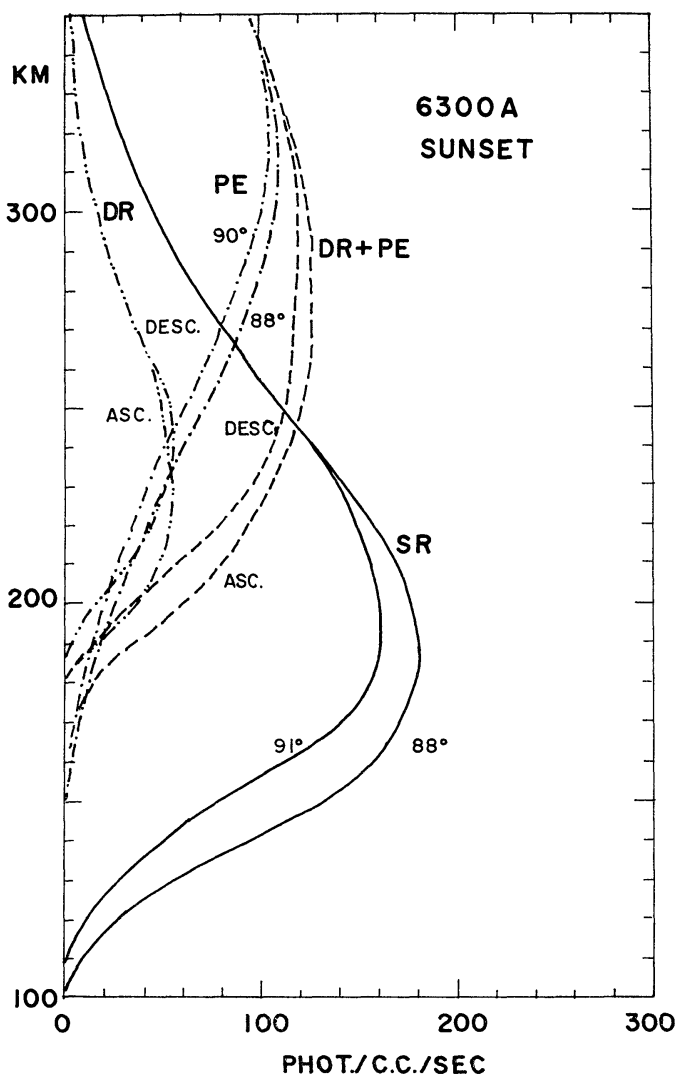

Fig. 1 The calculated emission rate profiles of the OI $6300 \AA$ glow for various excitation mechanisms, corresponding to the sunset condition (K-9M-20). interaction which is important for the calculation of the photoelectron energy spectrum above the $250 \mathrm{~km}$ level.

Figs. 1 and 2 illustrate the calculated emission profiles for various excitation mechanisms of the $6300 \AA$ and $3914 \AA$ emissions respectively.

\section{The $6300 \AA$ Emission}

To compare with the observed emission profile of the $6300 \AA$ dayglow, the excitation rates of the following were evaluated.

(i) Schumann-Runge dissociation of $\mathrm{O}_{2}$ by solar ultraviolet radiations (SR)

$$
\begin{aligned}
& \mathrm{O}_{2}\left(\mathrm{X}^{3} \Sigma_{g}{ }^{-}\right)+\mathrm{h} \nu= \\
& \mathrm{O}\left({ }^{1} \mathrm{D}\right)+\mathrm{O}\left({ }^{3} \mathrm{P}_{2,1,0}\right)
\end{aligned}
$$

(ii) Impact excitation of oxygen atom by solar XUV producing photoelectrons

$$
\mathrm{O}\left({ }^{3} \mathrm{P}\right)+\mathrm{e}=\mathrm{O}\left({ }^{1} \mathrm{D}\right)+\mathrm{e}
$$

(iii) Dissociative recombination of $\mathrm{O}_{2}{ }^{+}$and $\mathrm{NO}^{+}$with electrons 


$$
\begin{aligned}
& \mathrm{O}_{2}+\mathrm{e}=\mathrm{O}\left({ }^{1} \mathrm{D}\right)+\mathrm{O}^{*} ; \mathrm{k}_{3 \mathrm{~A}}, \\
& \mathrm{NO}+\mathrm{e}=\mathrm{O}\left({ }^{1} \mathrm{D}\right)+\mathrm{N}^{*} ; \mathrm{k}_{3 \mathrm{~B}} .
\end{aligned}
$$

In the previous analysis ${ }^{1}$, the processes (i) and (iii) were quantitatively studied. However, the process (ii) would be found to be important in the daytime excitation of the

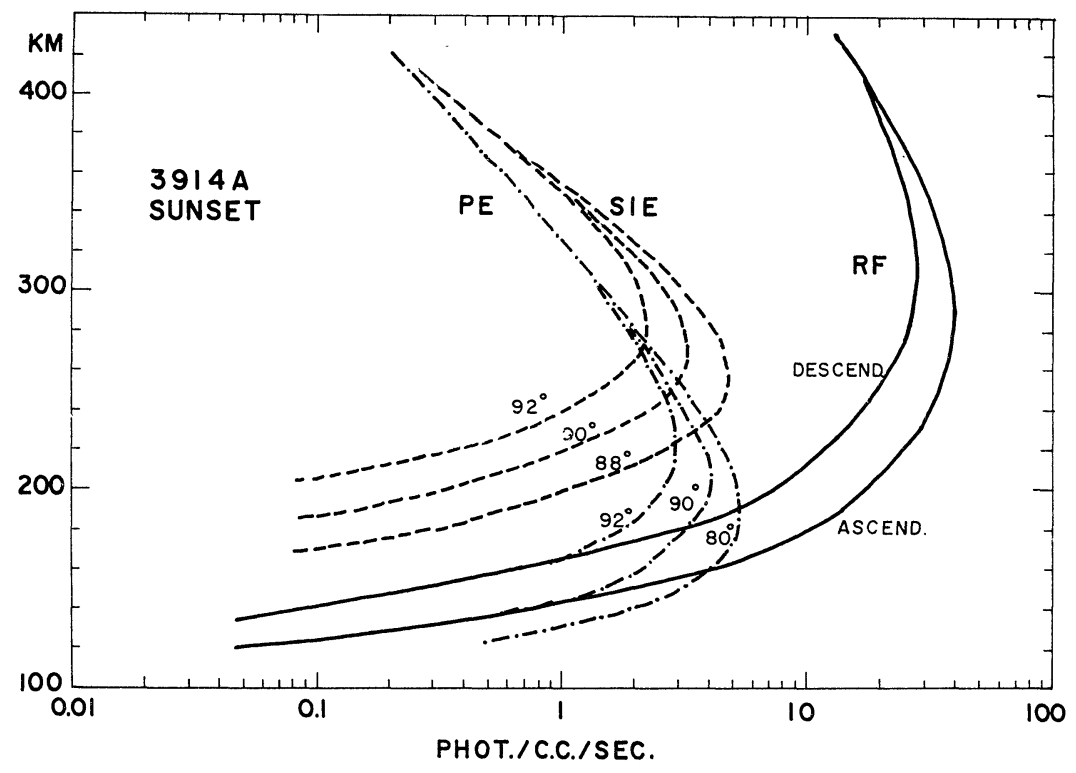

Fig. 2 The calculated emission rate profiles of the $\mathrm{N}_{2}+3914 \AA$ glow for various excitation mechanisms, corresponding to the sunset condition (K-9M-20).

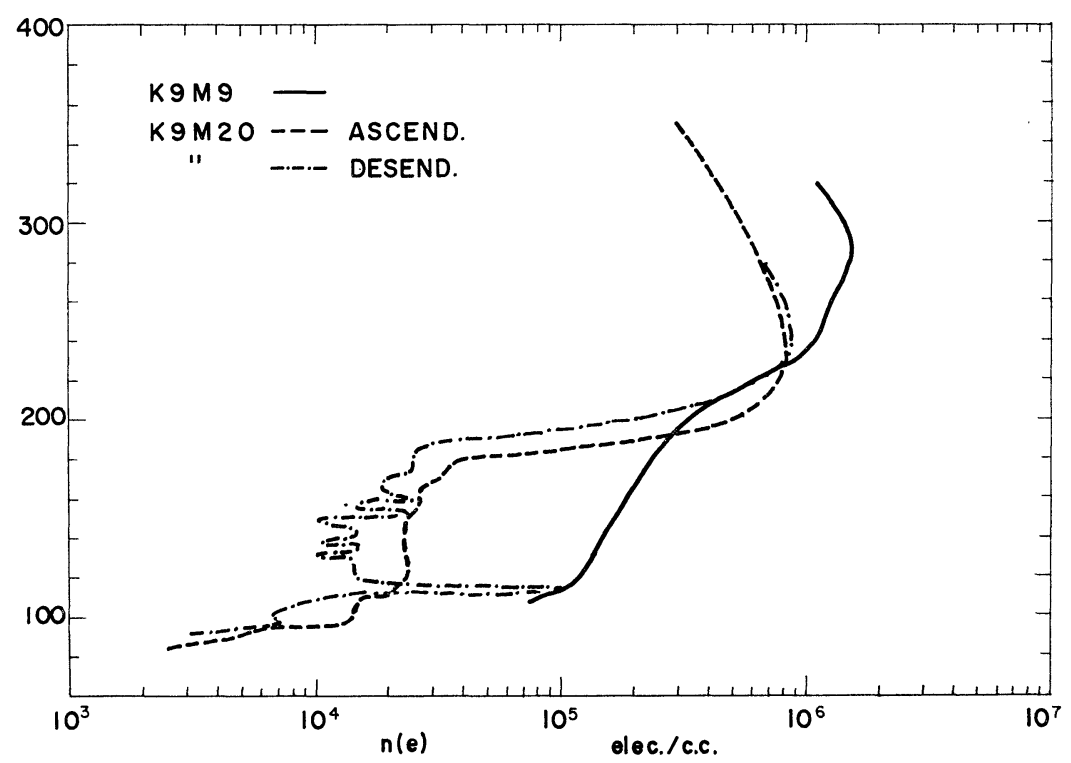

Fig. 3 The electron density profiles measured simultaneously with the present dayglow experiments (Courtesy of Prof. K. Hirao and Dr. H. Ôya). 
$6300 \AA$ Å emission.

The curves indicated by SR, PE, and DR in Fig. 4 show the altitude distributions of the $6300 \AA$ emission rate computed for the processes (i), (ii), and (iii) respectively. The DRprofile is obtained using the observed electron profile applied to the reaction rate coefficients, $\mathrm{k}_{3 \mathrm{~A}}=3 \times 10^{-12}$, and $\mathrm{k}_{3 \mathrm{~B}}=3 \times 10^{-13} \mathrm{~cm}^{3} / \mathrm{sec}$. The RE-profile is calculated on the basis of the electron energy flux spectrum after Ogawa ${ }^{2}$. The nitrogen molecule is considered as a quenching agent, with the rate coefficient of $2 \times 10^{-11} \mathrm{~cm}^{3} / \mathrm{sec}^{9}{ }^{9)}$ The altitude distributions of atmospheric parameters were taken from CIRA Model 2, Hour 14 $4^{3}$.

Similar calculations were repeated for the condition of K-9M-20, using the atmospheric parameters taken from CIRA Model 4, Hour 18. In Fig. 5 the integrated emission profile observed by K-9M-20 is compared with those calculated for SR, PE, and DR processes. In Figs. 4 and 5 one may notice that the observed profile is in favor of the theory which takes into account the photoelectron excitation. The rather slow decrease of the emission rate above $200 \mathrm{~km}$ cannot be explained by the SR-and DR-excitations alone. The results are summarized in Table 3. The observations show larger amplitude of variation of the $6300 \AA$ brightness than that obtained in the calculation. The observation in the sunset condition is particularly

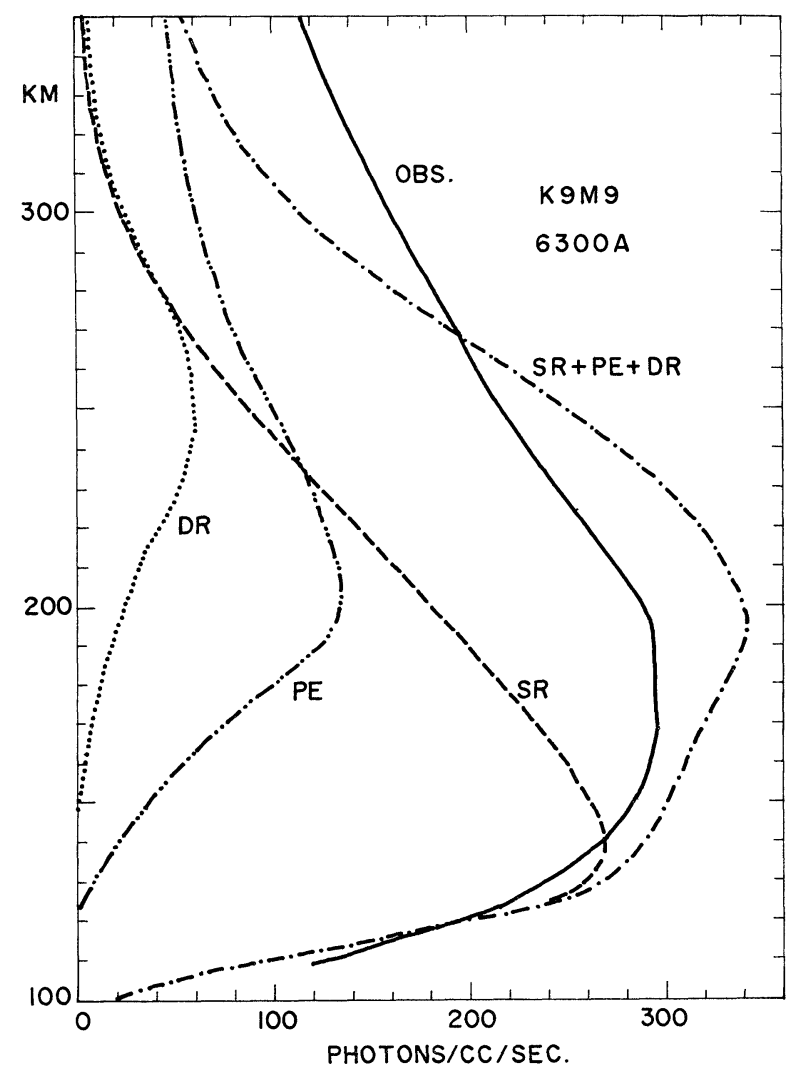

Fig. 4 Comparison of the observed and calculated emission profiles of the $6300 \AA$ dayglow observed in daytime condition (K-9M-9). 


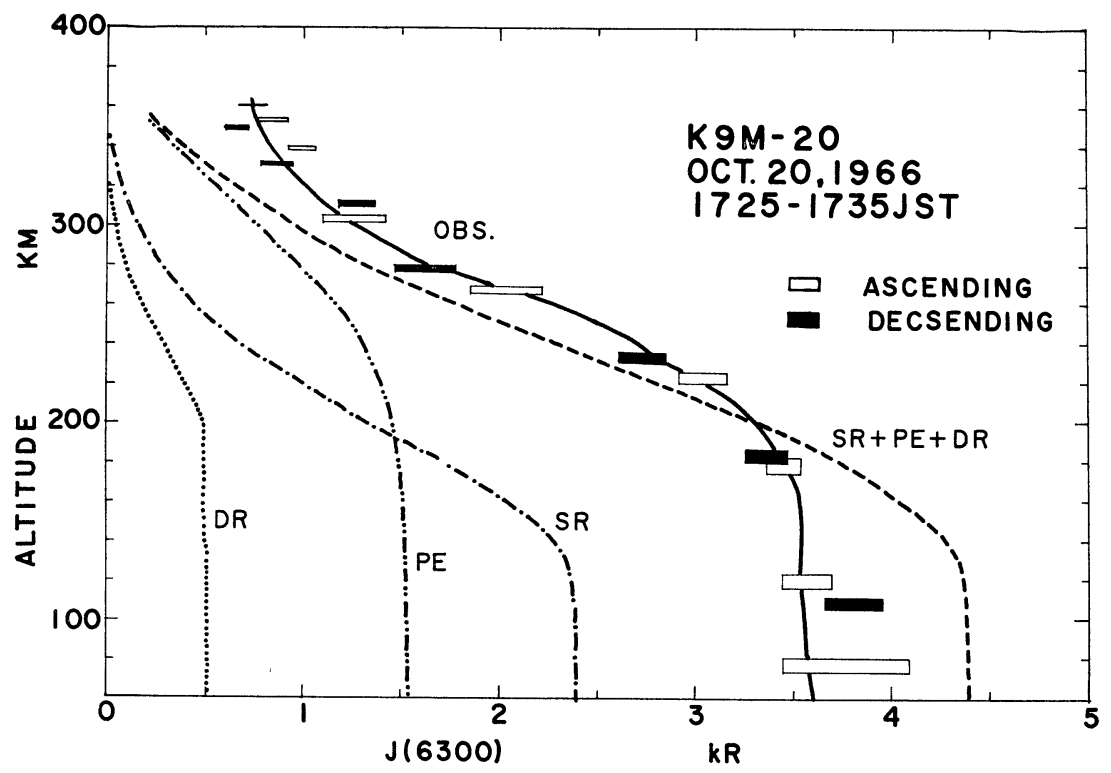

Fig. 5 Comparison of the observed and calculated (integrated) emission profiles of the $6300 \AA$ dayglow, observed in the sunset condition (K-9M-20).

Table 3. The Calculated Emission Rate of the $6300 \AA$ Dayglow below the $350 \mathrm{~km}$ Level

\begin{tabular}{c|c|c|c}
\hline \multicolumn{2}{c|}{ Solar zenish distance } & $37^{\circ}$ & $88^{\circ}-91^{\circ}$ \\
\hline \multicolumn{2}{c|}{ Corresponding flight } & $\mathrm{K}-9 \mathrm{M}-9$ & $\mathrm{~K}-9 \mathrm{M}-20$ \\
\hline \multirow{2}{*}{$\begin{array}{c}\text { Emission rate }(\mathrm{kR}) \\
\text { (Theory) }\end{array}$} & $\mathrm{SR}$ & 3.1 & 2.5 \\
\cline { 2 - 3 } & $\mathrm{DR}$ & 1.7 & 1.5 \\
\hline & Total & 0.6 & 0.5 \\
\hline \multicolumn{2}{c}{ Observed emission rate (kR) } & 5.4 & 4.5 \\
\hline
\end{tabular}

likely to indicate a smaller contribution of the SR glow than that can be extrapolated from the daytime result.

\section{The $5577 \AA$ Emission}

The $5577 \AA$ emission of atomic oxygen was observed only in the sunset condition. The record evidently indicates the presence of the two emitting layers, of which one is narrow and lies between 90 and $120 \mathrm{~km}$, and the other is broad and spread in the altitude range, $150-300 \mathrm{~km}$. The integrated emission rates are estimated to be about $400 \mathrm{R}$ and $300 \mathrm{R}$ for the narrow and broad layers, respectively. The scatter of the observed intensities did not permit the further quantitative analysis of the altitude distribution of the emission rate, however. 


\section{The $3914 \AA$ Emission}

To compare with the observed emission profile of the $3914 \AA$ dayglow, the excitation rates of the following processes were evaluated.

(i ) Resonance fluorescence of solar $3914 \AA$ A radiation by $\mathrm{N}_{2}{ }^{+}$ion $(\mathrm{RF})$,

(ii) Simultaneous ionization and excitation of $\mathrm{N}_{2}$ molecule by solar XUV radiations (SIE),

(iii) Impact excitation of $\mathrm{N}_{2}$ molecule by solar XUV producing photoelectrons (PE).

In the computation of the $\mathrm{RF}$ excitation rate, the equilibrium $\mathrm{N}_{2}{ }^{+}$density was obtained from the computed $\mathrm{N}_{2}{ }^{+}$source balanced with various removal processes of $\mathrm{N}_{2}{ }^{+4,5}$. The scattering coefficient was taken as 0.050 after Broadfoot ${ }^{6}$.

As summarized in Table 4, a large amplitude of intensity variation is expected for the $3914 \AA$ emission. This expectation is well demonstrated in the two experimental results illustrated in Fig. 6.

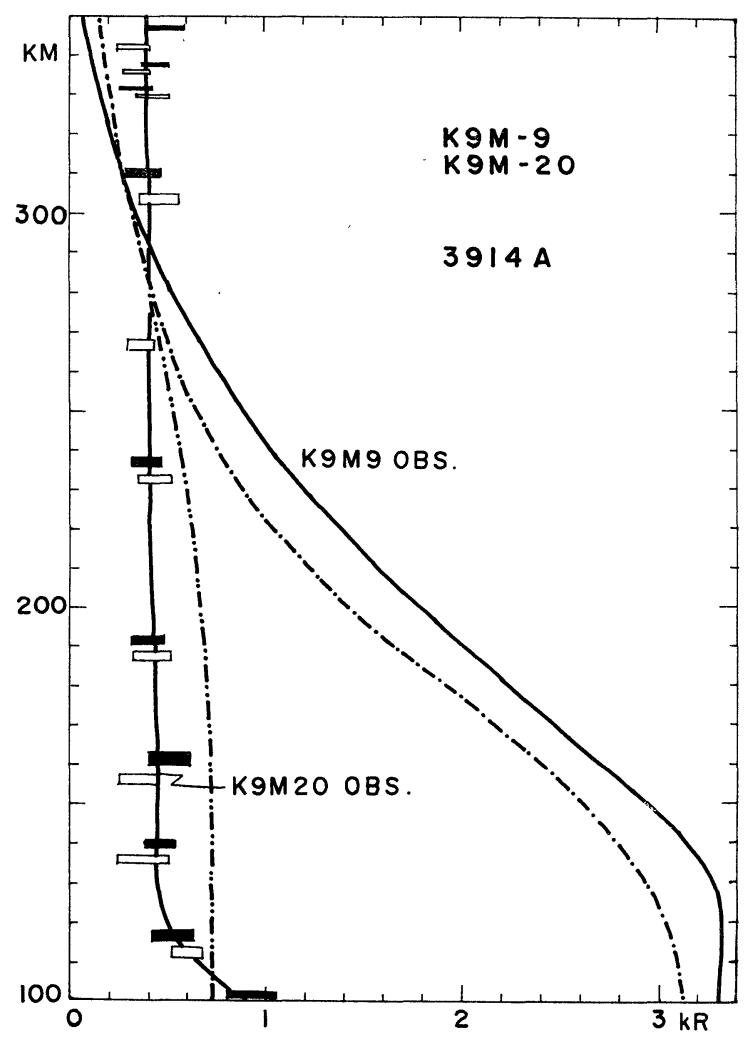

Fig. 6 Comparison of the observed and calculated (integrated) emission profiles of the $3914 \AA$ dayglow observed in two differfent conditions. -: observed, - - - : calculated for the daytime condition (sum of $\mathrm{RF}+\mathrm{SIE}+\mathrm{PE}$. - -.- calculated for the sunset condition (sum of RF+ $\mathrm{SIE}+\mathrm{PE})$. 
Table 4. The Calculated Emission Rate of the $3914 \AA$ A Dayglow below the $350 \mathrm{~km}$ Level

\begin{tabular}{l|c|c|c}
\hline \multicolumn{2}{l|}{ Solar zenith distance } & $37^{\circ}$ & $88^{\circ}-91^{\circ}$ \\
\hline \multicolumn{2}{l|}{ Corresponding fight } & K-9M-9 & K-9M-20 \\
\hline \multirow{3}{*}{ Emission rate (kR) } & RS & 1.39 & 0.66 \\
\cline { 2 - 4 } & $\mathrm{PE}$ & 0.45 & 0.05 \\
\cline { 2 - 4 } & $\mathrm{SIE}$ & 0.98 & 0.03 \\
\hline & Total & 2.82 & 0.74 \\
\hline \multicolumn{2}{l}{ Observed emissson rate (kR) } & 3.3 & 0.4 \\
\hline
\end{tabular}

\section{The Glow in the $2000 \sim 3000 \AA$ Range}

An ultraviolet glow was observed by the wide-dand photometer which was sensitive to radiation between 2000 and $3000 \AA$. . It was detected in the altitude ranges between 93 and $115 \mathrm{~km}$. The brightness in equivalence to $2500 \AA$ radiation was approximately $10 \mathrm{kR}$ at 93 $\mathrm{km}$, and decreased to $3 \mathrm{kR}$ at $115 \mathrm{~km}$. This brightness is too large to be interpreted by the Rayleigh scattering of solar radiations, and decreased with altitude more slowly than it should. It was not observed in the records of narrow band photometers sensitive to the radiations near $2150 \AA$ and $2500 \AA$. Therefore, the emission is likely to spread over the wide range between 2000 and $3000 \AA$. The emission may be ascribed to the unresolved bands of Schumann-Runge system of $\mathrm{O}_{2}$. Tohmatsu ${ }^{\text {) }}$ estimated that the resonance fluorescence of solar radiation by $\mathrm{O}_{2}$ may result in a ultraviolet glow in the mesosphere and lower thermosphere. However, the estimated intensity is larger than the observed, even by a factor of 20. It would mean that the efficiency of fluorescence is as low as 0.05 , if the observed emission is ascribed to the Schumann-Runge glow. This result is consistent with the spectroscopic observation by Barth ${ }^{8)}$.

\section{Acknowledgement}

The electron density- and temperature-data used in the present analysis are the courtesy of Prof. K. Hirao of the Institute of Space and Aeronautical Science, University of Tokyo (K-9M-9), and that of Dr. H. Ôya of the Ionosphere Physics Laboratory, Kyoto University.

\section{References}

1) T. Nagata, T. Tohmatsu, and T. Ogawa, Planet. Space Sci., 13 (1965) 1273.

2) T. Ogawa, to be published, (1968)

3) Cospar International Reference Atmosphere, 1965, (Pergamon Press, London, 1965)

4) E.E. Ferguson, F.C. Fehsenfeld, and A.L. Schmeltekopf, Space Research, 7 (1966) 135.

5) W.H. Kasner and M.A. Biondi, Phys. Rev., 137A (1965) 317.

6) A.L. Broadfoot and D.M. Hunten, Planet. Space Sci., 14 (1966) 1303.

7) T. Tohmatsu, Rep. Ion. Space Res., Japan, 17 (1963) 187.

8) C.A. Barth, Ann. de Geophys., 22 (1966), 198.

9) J.F. Noxon, Preprint (1968); L. Wallace and M.B. McElroy, Planet. Space Sci., 14 (1966) 677. 